\title{
The Impact of the NHL Lockout on County Employment
}

\author{
John Jasina* \\ Claflin University \\ School of Business \\ Kurt Rotthoff \\ Seton Hall University \\ Stillman School of Business
}

Spring 2015

\begin{abstract}
The National Hockey League (NHL) had a lockout that lasted the entire 2004-2005 season. Because this lockout cancelled the season, it provides a unique opportunity to analyze the economic impact on county employment and payroll in the sectors relevant to the sporting world. We test 3 and 4-digit NAICS codes, including Accommodation, Drinking Places, Restaurants, and Spectator Sports. Using the impact found in a county with an NHL team, relative to trends in the surrounding counties, we find no general impact on employment, but we find a decrease in payroll in some sectors.
\end{abstract}

JEL: Z23, L83

\footnotetext{
* John Jasina can be contacted at: jjasina@ claflin.edu, Claflin University, 400 Magnolia St., Orangeburg, SC 29115 and Kurt Rotthoff at: Kurt.Rotthoff@ shu.edu or Rotthoff@ gmail.com , Seton Hall University, JH 621, 400 South Orange Ave, South Orange, NJ 07079. We would like to thank Skip Sauer, Pete Groothuis, Sean Mulholland, Rey Hernandez-Julian and the participants at the 2013 Association of Private Enterprise Education's annual meetings for the helpful comments. Any mistakes are ours.
} 


\section{Introduction}

Local economies can be devastated when a local company shuts down. The jobs, and subsequent incomes, of those working within the firm are lost, even if the shut-down is temporary. In this study we measure the temporary (one year) shut-down of the National Hockey League (NHL) during its lockout year, 2004-2005, where the entire season was cancelled for the lockout. ${ }^{1}$ We establish a structure to measure the impact of this lockout, which allows us to separate out locational trends and time trends from the event itself.

The local economic impact of professional sports franchises has been studied by Baade and Dye (1988, 1990), Baade (1996), Baade and Sanderson (1997), Coates and Humphreys (2003), and Jasina and Rotthoff (2008). Most of these papers use MSAs (Metropolitan Statistical Areas) as a unit of observation. ${ }^{2}$ However, Jasina and Rotthoff (2008) use county level data to estimate the economic impact of franchises entering or leaving at a more local (county) level, following the MSA analysis done in Coates and Humphreys (2003). Both Coates and Humphreys and Jasina and Rotthoff find some positive impact, and in some cases a negative impact, of having a sports franchise enter an area (and vice-versa for franchises leaving an area). The general finding is that the area revitalization which occurs is due to a consumption shift from one area of town to another (moving the jobs near the stadium from other areas of town). This explanation is consistent with the story of how some sectors have a positive effect, but are offset by comparable negative effects in other sectors of the economy. We expand the research on the more local, county, level.

\footnotetext{
${ }^{1}$ This work stoppage is the first in history where the entire season was cancelled for major sports league.

2 Baade and Dye (1988, 1990), Baade (1996), Baade and Sanderson (1997), Coates and Humphreys (2001), Coates and Humphreys (2003), and Winfree and Fort (2008) all use MSAs as their measurement.
} 
Other studies have focused on the impact of strikes in sports. Coates and Humphreys (2001) examine strikes in football and baseball, between 1969 and 1996, and find that there was no economic impact during the strikes and no impact in the years following the strikes. Given the findings in Winfree and Fort (2008), which find that the NHL strikes lead to a substitution from professional hockey to other forms of hockey (junior league and minor league), these findings are expected.

We expand our ability to measure these economic impacts by measuring the impact of the lockout season, 2004-2005, on the employment and payroll of four industries at the county level. In addition to looking at the counties that have NHL teams, we include border counties as a control group to capture any regional impacts that occur during the study. We also include yearly time trends to control for existing trends in these different regions. This allows for the control of general trends, both regional and annual, to accurately isolate the local economic impact of the sports franchises.

The NHL's 2004-2005 yearlong lockout provides a natural experiment where the employees were not working with the NHL during the lockout. During this time period, there was also no consumer spending within the NHL. The NHL did resume play the following season, in the fall of 2005. When the NHL faced another potential lock-out before the 2012 season the economic development consultancy firm, Camoin Associates, estimated that a lost season would cost Long Island an estimated 1,000 jobs and $\$ 62$ million in spending. ${ }^{3}$ This is the estimate for only one of the 30 NHL teams, implying that the local economic impacts of a season long lockout could be massive. Using data

\footnotetext{
${ }^{3}$ From Michael N'Dolo's interview with NPR's marketplace: http://www.marketplace.org/topics/business/hockey-lockout-again-hurts-smallbusinesses?utm_source=feedburner\&utm_medium=feed\&utm_campaign=Feed\%3A+APM_Marketplace+ $\% 28 \mathrm{APM} \% 3 \mathrm{~A}+$ Marketplace\%29
} 
from before, during, and after the 2004-2005 season's NHL lockout we find a decrease in employment in only one of the four relevant industries. However, we do find that payroll falls in three of the four industries. Our findings of little to no employment impact are consistent with the substitution effects found in Winfree and Fort (2008). The next section looks at the data used in this study, followed by the methodology. The results are presented in section four, followed by a robustness check. The final section concludes.

\section{Data}

To accurately measure the impact of the 2004-2005 NHL lockout we use county employment and county quarterly payroll figures in sports related industries. We collect employment and payroll data from the US Census Bureau's County Business Pattern (CBP) database for Performing Arts, Spectator Sports, and Related (711), Accommodation (721), Drinking Places (7224), and Full Service Restaurants (7221). All payroll data are in 2002 dollars. The NHL season occurs over the winter, and thus spans two calendar years. Play begins during the fall of one year and ends the following spring. To ensure that we accurately measure the impact of the lockout, we use the CBP, which provides data for employment during the week of March 12. Payroll data are from the first quarter payroll, which align with each hockey season. These data allow an accurate measure of the NHL's impact because the regular season goes through April; thus these data include all season impacts on these sectors.

Using CBP data, we capture general economic conditions with broader measures of employment and payroll. In both the employment and payroll regressions we include state and national employment and payroll controls, respectively, to capture the general trends for each industry. We also include county-specific explanatory variables to capture 
local economic conditions. These include county population, growth rate, and county unemployment rate. Following Coates and Humphreys (2003), we include a lagged dependent variable in each regression. They argue that the inclusion of the lagged dependent variable only biases the lagged dependent variable, and does not bias parameters of the independent variables. To match the March employment data and payroll data, we use the Bureau of Labor Statistics' March unemployment rate for each county. Population growth rates were calculated using Census Bureau population data.

To perform our analysis we construct a sample that includes 142 counties, of which twenty five were home to an NHL team during our sample period. ${ }^{4}$ Following Coates and Humphreys (2003), we limit our sample to U.S. counties due to the difficulty of finding comparable economic data. The remaining counties in our data, excluding any border county that is in a different state, are border counties to these NHL counties. ${ }^{5}$ Given the amount of previous research that use MSAs as the geographic measure, our goal is to narrow the geographic area of interest and avoid problems associated with changes in MSA definitions and lost information which occur due to the overall size of the MSA.

Our sample period runs from 2001 through 2009. The lockout year occurred during the 2004-2005 hockey season. Thus, given the structure of the employment and payroll data, 2005 is our year of interest. We have four full years of data prior to the lockout and four full years of data following the lockout. Our dependent variable includes data for 2000 to allow for a lagged dependent variable throughout the sample. Summary statistics for NHL counties can be found by industry code in Table 1. Employment in the

\footnotetext{
${ }_{5}^{4}$ Arena data come from http://www.ballparks.com/

${ }^{5}$ We refrain from including border counties that cross state lines in order to avoid differences in economic factors that could contribute to differences in employment and payroll.
} 
NHL counties is higher than employment in the border counties for each industry group. This is expected since sports franchises are usually located in more populous geographic areas.

[Table 1]

\section{Empirical Model}

We estimate separate linear models to determine employment and payroll for each of the NAICS codes described above in equation 1. Our model takes the general form

$$
y_{j i t}=\alpha+\beta_{i} Y_{i}+\gamma_{t} I_{t}+\delta_{N H L}+X_{i t}^{\prime} \xi+\mu_{j i t}
$$

where $y_{j i t}$ is the dependent variable, either employment or payroll for a specific NAICS code, $i$ indexes counties, $t$ indexes time, in years, and $j$ indexes either employment or payroll in a particular industry. $Y_{i}$ and $I_{t}$ are year and county fixed effects, respectively. The variable $\delta_{N H L}$ is a dummy variable equal to 1 for NHL counties in year 2005 and 0 otherwise. The impact of the lockout on $y_{j i t}$ in NHL counties, is captured by $\delta_{N H L} . X_{i t}^{\prime}$ is a vector of explanatory variables that capture national economic conditions within each industry, and explanatory variables that capture county economic conditions, such as county unemployment, population growth rate, and a lagged dependent variable. We first estimate a fixed effect model, correcting for heteroskedasticty. The results of which are reported in Table 2. An alternative specification is described below.

The counties in our sample are likely to exhibit some cross-sectional dependence given the geographic location to one another. We would expect some unobserved factors or shocks to impact both the NHL counties as well as the border counties. We implement three tests for cross-sectional dependence proposed by Pesaran (2004), Friedman (1937), and Frees (1995). De Hoyos and Sarafidis (2006) outline the three methods for testing for 
cross-sectional dependence for panels with $T<N$. Although each test can be used with unbalanced panels, we were unable to conduct the Friedman and Frees tests in some cases because of the small $T$ of our sample. It became necessary to drop counties with missing data in order to perform the Friedman and Frees tests. This was performed separately for each industry code and each dependent variable in our dataset. All three tests confirm the presence of cross-sectional dependence in each industry in our sample.

We test for serial correlation using the method discussed in Wooldridge (2002). Drukker (2003) demonstrates that Wooldridge's test is robust even in small samples. The null hypothesis of no serial correlation is rejected for each industry code and dependent variable in our sample. We also test for groupwise heteroskedasticity using the modified Wald statistic from Greene (2000). We follow the same procedure as the previous tests. The test confirms the presence of groupwise heteroskedasticity in each industry and each dependent variable in our sample

Given the results of the above tests, we correct for groupwise heteroskedasticity, serial correlation and cross-sectional dependence using the methods outlined in Hoechle (2007). This method is valid for balanced and unbalanced panels and according to Hoechle (2007), "Although Driscoll and Kraay standard errors tend also to be slightly optimistic, their small sample properties are significantly better than those of alternative covariance estimators when cross-sectional dependence is present" (p. 2). Using Driscoll and Kraay standard errors requires assigning a lag length during the estimation process. We use a lag length of one period. Alternative lag lengths did not significantly impact the estimated standard errors in our regressions. Our alternative model is estimated using pooled OLS and fixed effects with Driscoll and Kraay standard errors. 


\section{Results}

Although the lockout lasted the entire 2004-2005 season, we find little evidence to support the argument that the prolonged NHL lockout had a significant negative impact on county employment. Stadium boosters often cite the Accommodation sector as one of the primary beneficiaries of publicly financed sports stadiums. If this is true we should see a decline in employment during the year long NHL lockout. We find no support for this claim. As seen in Table 2 the impact of NHL lockout has no significant impact on employment in NHL counties.

[Table 2]

The first column in Table 2 shows the impact of the NHL lockout on employment in NHL counties for each of the industries in our study. Employment in Performing Arts, Spectator Sports, and Related (711) is not statistically significant even though this NAICS code includes NHL players and team related employment. Given that there is a maximum of 23 players on a club's roster, the number of NHL players is small compared to the overall employment in these sectors. The mean employment in Performing Arts, Spectator Sports, and Related the mean employment is 6,238.

Three service industries, Accommodation (721), Drinking Places (7224) and Full Service Restaurants (7221), are said to be primary destinations for sports fans. If true, we should see a negative impact as a result of the prolonged lockout. We find the lockout had no statistically significant impact on employment in the Accommodation industry. During the lockout year, employment in Drinking Places falls by 150 in NHL counties. This represents a 5.4\% decline in employment in Drinking Places during the NHL 
lockout. The change in employment in Full Service Restaurants was not statistically significant.

Given a decline in employment we would expect payrolls in Drinking Places to decrease during the lockout year. In NHL counties the coefficient on payroll, Table 3, in the lockout year is -400 and is statistically significant at the $1 \%$ level. This means that payrolls in Drinking Places declined by $\$ 400,000$ as a result of the lockout. This represents a decline of about $4.4 \%$ in first quarter payroll for these NHL counties. Although we do not see a decline in employment in Full Service Restaurants, we do find a decline in first quarter payroll in NHL counties. Payroll declined by $-2,110$, or $\$ 2,110,000$, in NHL counties.

[Table 3]

Any form of direct impact from the NHL lockout can be measured in the payroll in Performing Arts, Spectator Sports, and Related (NAICS 711). The estimated coefficient in the Performing Arts, Spectator Sports, and Related regression is -20,290, and is significant, representing a $17.8 \%$ decline in payroll in the mean NHL county.

Given that there are 23 hockey players on each team, and teams had an average payroll of over $\$ 44$ million during the 2003-2004 season, these findings represent an insignificant impact for workers in these two sectors when the NHL players are excluded. ${ }^{6}$ Given that the average NHL player's contract is nine months, dividing this number by three gives the quarterly estimate of $\$ 14.8$ million for each of these teams. The loss of the players' salaries during this quarter represents a change in the estimated coefficient of 14,800 . Thus the estimated impact to the rest of the Performing Arts,

\footnotetext{
${ }^{6}$ The average salary for each team during the 2003-2004 hockey season was $\$ 44,400,490.23$; from USA Today: http://content.usatoday.com/sportsdata/hockey/nhl/salaries/team/2003.
} 
Spectator Sports, and Related excluding the NHL players would cause an estimated coefficient of 2,800.26. This estimate is also insignificant. These results support the idea that there is a consumption shift in these counties when the NHL is not playing.

\section{Robustness}

To test the results found in the previous section, we employ two alternative specifications which confirm these findings. Given that our data includes both large and small counties, we first test the data by eliminating all observations below the 5th percentile and all observations above the 95th percentile. For example, in the Full Service Restaurant sector, Hardee County, FL has employment below 100, Cheatham County, TN below 150 while Cook County, IL and New York County, NY has employment greater than 60,000 and Los Angeles County, CA has employment greater than 115,000. This structure allows us to measure if the results are being driven by the largest, or smallest, counties in the data. The second robustness test follows equation (1), but eliminates the state and national independent variables for employment and payroll. This second check will verify that the results are not being driven by state or national controls. [Table 4]

Table 4 displays the results for the modified employment regressions for both robustness checks: dropping the top and bottom 5\% of counties (by employment) and excluding state and national controls. The results in both samples are consistent with our previous findings; we continue to find a negative and significant impact on the employment in drinking places. In both robustness checks we also find a negative but insignificant impact in the Performing Arts, Spectator Sports, and Related industry. [Table 5] 
Testing both of these robustness measures on payroll continues to give results similar to those given by the general models. We find a decline in payroll for Drinking Places in both regressions. We also find, for NHL counties, payroll declines in the Performing Arts, Spectator Sports, and Related industries. The exception is payroll in Full Service Restaurants in no longer statistically significant in either robust check models.

\section{Conclusion}

The public often debates the impact of sports franchises and how they impact the local economy. We use local data, data at the county level rather than the MSA level, and measure a county's economic impact in counties with an NHL franchise relative to border counties that do not have an NHL team. This structure also allows us to control for local trends that can be specific to each local economy. With these controls, we find that the NHL lockout had little impact on employment in the expected industries within a county. However, we do find a negative impact on the payroll of many of the expected industries during the NHL lockout period.

Only one of the four industries, Drinking Places, shows a decrease in employment in the NHL counties during the lockout year. Three of the four industries show a significant decrease in payroll in the NHL counties. However, it is possible that three of these industries' negative payroll impacts are driven by the loss of hockey player salaries, and not necessarily a loss in income to local citizens. This is also confirmed by the increase in wages for non-NHL counties. These results also provide evidence that there is a consumption shift as found in Coates and Humphreys (2003) and Jasina and Rotthoff (2008). 
The use of the NHL's lockout period along with the use of border counties, for local controls, allows for a unique analysis of the local economic impact of professional sports franchises. The NHL's 2004-2005 lockout period continues to support the existing literature on the local impact of employment and payroll. 


\section{References}

Baade, R. A. (1996). Professional sports as catalysts for metropolitan economic development. Journal of Urban Affairs, 18(1), 1-17.

Baade, R. A. and Dye. R. F. (1988). An analysis of the economic rationale for public subsidization of sports stadiums. The Annals of Regional Sciences, 22(2), 37-47.

Baade, R. A. and Dye, R. F. (1990). The impact of stadiums and professional sports on metropolitan area development. Growth and Change, 1-14.

Baade, R. A. and Sanderson, A. R. (1997). The employment effect of teams and sports facilities. Sports, Jobs and Taxes: The Economic Impact of Sports Teams and Stadiums. Washington, DC: Brookings Institute.

Coates, D. and Humphreys, B.R., (2001). The economic consequences of professional sports strikes and lockouts. Southern Economic Journal 67 (3), 737-747.

Coates, D. and Humphreys, B.R. (2003). The effect of professional sports on earnings and employment in the services and retail sectors in US cities. Regional Science and Urban Economics 33, 175-198.

De Hoyos, R. E. and Sarafidis, V. (2006). Testing for cross-sectional dependence in panel-data models. The Stata Journal, 6 (4), 482-496.

Drukker, D. M. (2003). Testing for serial correlation in linear panel-data models. The Stata Journal, 3 (2), 168-177.

Frees, E. W. (1995). Assessing cross-sectional correlation in panel data. Journal of Econometrics, 69 (2), 393-414.

Friedman, M. (1937). The use of ranks to avoid the assumption of normality implicit in the analysis of variance. Journal of the American Statistical Association, 32 (200), 675-701.

Greene, W. H. (2000). Econometric Analysis (4th ed.). Upper Saddle River, NJ: PrenticeHall, Inc.

Hoechle, D. (2007). Robust standard errors for panel regression with cross-sectional dependence. The Stata Journal, 7 (3), 281-312.

Jasina, J. and Rotthoff, K. W. (2008). The Impact of a Professional Sports Franchise on County Employment and Wages International Journal of Sport Finance November, Vol. 3, Is. 4 
Pesaran, M. H. (2004). General diagnostic tests for cross section dependence in panels. Working paper. Retrieved from http://papers.ssrn.com/sol3/papers.cfm?abstract_id=572504

Winfree, J. A. and Fort, R. (2008). Fan Substitution and the 2004-05 NHL Lockout. Journal of Sports Economics 9: 425

Wooldridge, J. M., (2002). Econometric analysis of cross section and panel data. Cambridge, MA: MIT Press. 
Table 1

Employment and Payroll in Performing Arts, Spectator Sports, and Related

(NAICS 711)

\section{NHL Counties}

\begin{tabular}{lrrrrr} 
Variable & Obs. & Mean & Std. Dev. & Min & Max \\
\hline Employment & 217 & 6238 & 9173 & 587 & 39280 \\
First Quarter Payroll & 214 & 114211 & 173239 & 4569 & 911753 \\
Border Counties & & & & & \\
Variable & Obs. & Mean & Std. Dev. & Min & Max \\
\hline Employment & 560 & 852 & 1180 & 2 & 7813 \\
First Quarter Payroll & 584 & 9441 & 18589 & 5 & 111800
\end{tabular}

Employment and Payroll in Accommodation (NAICS 721)

\begin{tabular}{lcrrrr}
\hline NHL Counties & & & & & \\
Variable & Obs. & Mean & Std. Dev. & Min & Max \\
\hline Employment & 225 & 11877 & 10883 & 1294 & 44597 \\
$\begin{array}{l}\text { First Quarter Payroll } \\
\text { Border Counties }\end{array}$ & 225 & 76826 & 87044 & 5558 & 489975 \\
Variable & & & & & \\
\hline Employment & Obs. & Mean & Std. Dev. & Min & Max \\
First Quarter Payroll & 950 & 2285 & 4534 & 9 & 37806 \\
& 951 & 12275 & 27705 & 18 & 267508
\end{tabular}

Employment and Payroll in Drinking Places (NAICS 7224)

\begin{tabular}{lrrrrr}
\hline NHL Counties & & & & & \\
Variable & Obs. & Mean & Std. Dev. & Min & Max \\
\hline Employment & 225 & 2755 & 2416 & 491 & 11690 \\
$\begin{array}{l}\text { First Quarter Payroll } \\
\text { Border Counties }\end{array}$ & 225 & 9122 & 9574 & 1311 & 49310 \\
Variable & & & & & \\
\hline Employment & Obs. & Mean & Std. Dev. & Min & Max \\
First Quarter Payroll & 739 & 575 & 690 & 1 & 5461 \\
& 755 & 1661 & 2262 & 2 & 19818
\end{tabular}

Employment and Payroll in Full Service Restaurants (NAICS 7221)

\section{NHL Counties}

\begin{tabular}{lrrrrr} 
Variable & Obs. & Mean & Std. Dev. & Min & Max \\
\hline Employment & 225 & 30796 & 28340 & 5478 & 144795 \\
First Quarter Payroll & 225 & 120981 & 123903 & 19726 & 623049 \\
Border Counties & & & & & \\
Variable & Obs. & Mean & Std. Dev. & Min & Max \\
\hline Employment & 967 & 7108 & 8158 & 54 & 52744 \\
First Quarter Payroll & 967 & 24659 & 30988 & 106 & 216844
\end{tabular}


Table 2 Employment Regressions

\begin{tabular}{lrr} 
Industry (NAICS) & Fixed Effect & Alternative \\
& Model & Specification \\
\hline Performing Arts, Spectator Sports, and Related & -86 & -86 \\
(711) & $(137)$ & $(98)$ \\
Accommodation (721) & -74 & -72 \\
& $(122)$ & $(130)$ \\
Drinking Places (7224) & $-150^{* * *}$ & $-150^{* * *}$ \\
& $(46)$ & $(10)$ \\
Full Service Restaurants (7221) & 244 & 244 \\
& $(240)$ & $(249)$ \\
\hline
\end{tabular}

Notes: Standard Error in parenthesis. *** Significant at the 1 percent level, ** Significant at the 5 percent level, and * Significant at the 10 percent level. Estimates are in the number of jobs within that industry. Each regression controls for state and national employment, county population growth rate, county unemployment rate, and lagged dependent variables.

Table 3 Payroll Regressions

\begin{tabular}{lrr} 
Industry (NAICS) & \multicolumn{1}{c}{ Fixed Effect } & \multicolumn{1}{c}{$\begin{array}{c}\text { Alternative } \\
\text { Sodel }\end{array}$} \\
\hline Performing Arts, Spectator Sports, and Related & $-20,290^{* * *}$ & $-20,290^{* * * *}$ \\
(711) & $(5017)$ & $(1010)$ \\
Accommodation (721) & 1,120 & 1,123 \\
& $(1155)$ & $(1090)$ \\
Drinking Places (7224) & $-400^{* * *}$ & $-400^{* * *}$ \\
& $(142)$ & $(71)$ \\
Full Service Restaurants (7221) & $-2,110^{* * *}$ & $-2,110^{* *}$ \\
& $(783)$ & $(897)$ \\
\hline
\end{tabular}

Notes: Standard Error in parenthesis. *** Significant at the 1 percent level, ** Significant at the 5 percent level, and * Significant at the 10 percent level. Payroll is in thousands of dollars. Each regression controls for state and national payroll, county population growth rate, county unemployment rate, and lagged dependent variables. 
Table 4 Employment Regressions, Modified Sample

\begin{tabular}{lr|r}
\hline & $\begin{array}{c}\text { Without top and bottom } \\
5 \% \text { of counties } \\
\text { (by employment) }\end{array}$ & \multicolumn{2}{c}{$\begin{array}{c}\text { Without national and } \\
\text { state controls }\end{array}$} \\
\cline { 2 - 3 } Industry (NAICS) & -120 & \multicolumn{2}{c}{ NHL County } \\
\cline { 2 - 3 } Performing Arts, Spectator & $(83)$ & -126 \\
Sports, and Related (711) & -105 & $(86)$ \\
Accommodation (721) & $(90)$ & -64 \\
Drinking Places (7224) & $-114 * * *$ & $(124)$ \\
Full Service Restaurants & $(9)$ & $-161 * * *$ \\
(7221) & -67 & $(11)$ \\
& $(135)$ & 233 \\
& & $(243)$ \\
\hline
\end{tabular}

Notes: Standard Error in parenthesis. *** Significant at the 1 percent level, ** Significant at the 5 percent level, and * Significant at the 10 percent level. Estimates are in the number of jobs within that industry. Each regression controls for state and national employment, county population growth rate, county unemployment rate, and lagged dependent variables.

Table 5 Payroll Regressions, Modified Sample

\begin{tabular}{lr|r}
\hline & $\begin{array}{c}\text { Without top and bottom 5\% of } \\
\text { counties } \\
\text { (by employment) }\end{array}$ & \multicolumn{2}{c}{$\begin{array}{c}\text { Without national and } \\
\text { state controls }\end{array}$} \\
\cline { 2 - 3 } \multicolumn{1}{c}{ Industry (NAICS) } & $-18,888^{* * *}$ & NHL County \\
\hline Performing Arts, Spectator & $(2489)$ \\
Sports, and Related (711) & 2,396 & $-23,644 * * *$ \\
Accommodation (721) & $(1607)$ & $(2297)$ \\
Drinking Places (7224) & $-446 * *$ \\
Full Service Restaurants & $(97)$ & 2,823 \\
(7221) & $-1,149$ & $(1816)$ \\
& $(1143)$ & $-510^{* * *}$ \\
& & $(116)$ \\
\hline
\end{tabular}

Notes: Standard Error in parenthesis. *** Significant at the 1 percent level, ** Significant at the 5 percent level, and * Significant at the 10 percent level. Payroll is in thousands of dollars. Each regression controls for state and national payroll, county population growth rate, county unemployment rate, and lagged dependent variables. 